\title{
Stakeholder Preferences in Advanced Public Transportation System Planning
}

\author{
Jonathan Levine \\ Soonae Park \\ Steven E. Underwood \\ RichardR. Wallace \\ The University of Michigan
}

\begin{abstract}
Transportation planning in general and planning for intelligent transportation systems (TTS) in particular are notable both for multiple goals and for multiple constituencies. In response to complex policy environments such as this, multicriteria decision analysis often was utilized to assist in the evaluation of alternative investments or policy directions. This approach is extended here to assess stakeholder valuation of broad goals of an ITS planning process, the Suburban Mobility Authority for Regional Transportation (SMART) operational field test in the metropolitan Detroit area. Two levels of goals were considered: broad system-wide goals (e.g., energy savings, interagency coordination, congestion reduction) and specific service characteristics, such as advance reservations, scheduling, and reliability. Using a modified Analytical Hierarchy Process,

The authors wish to thank the Suburban Mobility Authority for Regional Transportation for research funding, and all of those who participated in our stakeholder interviews and focus groups. We also want to acknowledge the special assistance provided by the SMART staff who helped with access to facilities and participants. Finally, thanks to Tracy Gao and Zakia Shaikh of the University of Michigan for assistance in administering the survey questionnaires.
\end{abstract}


implicit preference weights for transportation planning goals were derived, and inter-and intragroup comparisons were made. Overall, there was less variation between groups in preferences than might be expected, indicating a fair degree of common ground in desired outcomes of transit planning. The ability to provide for the trips that people request, referring both to the accommodation of trips and the match between requested and scheduled times, were important goals across various stakeholder groups. Similarty, the provision of reliable service was generally valued highly. Information provision appears to be a lower priority. Thus, to the extent that automatic scheduling and dispatch assists improved scheduling, trip reservation, and routing, it is likely to meet stakeholders'preferences.

The study characterizes the various groups' preferences for transit service along a continuum ranging from "expansive" to "incremental." The expansive vision seeks to develop new forms of service for transit and paratransit customers better, while under the incremental view, consolidation of and improvements to existing service are a higher priority. The expansive position appears most clearly among citizens'groups, social service agencies, and business people. The business community is particularly interested in expansion of the hours of service, presumably to facilitate travel by customers or employees during evenings and weekends. The more incremental view is held by transportation professionals and SMART employees who are aware of the constraints under which they work.

\section{Introduction}

Advanced Public Transportation Systems (APTS) represent a diverse market basket of technologies and applications (Khattak et al. 1996). In planning for APTS adoption, public transportation organizations need to make decisions among technologies (e.g., automatic vehicle location, passenger counting, digital communication) and their application (e.g., paratransit routing and dispatch, traffic signal preemption, real-time information provision, fixed-route transfer coordination). Priority setting in this environment is likely to incorporate views regarding the preferences of different groups, with potential for both consensus and conflict. This study explores the interests of diverse stakeholder groups to a process of APTS implementation within metropolitan Detroit by the SMART (Suburban Mobility Authority for Regional Transportation) transit district. Within the national program of Intelligent Transportation Systems (ITS) field tests, SMART seeks to apply advanced technolo- 
gies, including automatic vehicle location and automatic scheduling and dispatch to its paratransit operations. As part of the evaluation of these efforts, this study aims to understand the relevant priorities of various groups in the region and how these may influence SMART's effort to improve services for its customers and communities by using APTS.

Given a public policy environment that is characterized by various objectives and constituencies, a search for a unitary social valuation within the SMART APTS deployment is probably futile. By reducing varied impacts to commensurate terms and masking actual variations in preferences, such analysis might limit the role of public debate regarding the directions of APTS deployment. For these reasons, a study of stakeholder groups and their preferences and priorities for system design is presented here. Information of this sort may be combined with knowledge regarding system outcomes to analyze the desirability of the systems from the perspectives of the various groups.

This study employs both qualitative and quantitative evaluations of stakeholder preferences. The former was designed as important input to the quantitative portion of the stakeholder preference analysis in that it established relevant groups and goals for further quantitative analysis. The study finds a relative consensus on the importance of transit mobility-related goals (as opposed to ancillary benefits such as interagency coordination or general congestion reduction) but disagreements on which mobility goals to pursue. In particular, some groups tend to focus on improving functions that are already being provided, while others will seek to use technological advances as a platform for broadening the scope of paratransit services.

\section{Preference Measurement in Transportation Evaluation}

The planning, marketing, and operations research literature abounds with approaches to multiattribute analysis in decisionmaking. Methodologies such as Multiattribute Utility Theory (Keeney and Raiffa 1976), Analytic Hierarchy Process (Saaty 1930; Saaty and Keams 1985), TODIM (Gomes 1989), and ELECTRE (Boy and Hugonnard 1982) share a similar underpinning: the notion that decisions entailing multiple objectives are aided by specifying quantified outcomes and preferencebased weighting schemes. The quantitative ratings generated by these methods are 
seen as tools for stakeholders and decisionmakers to compare simultaneously more alternatives and attributes than they would have been capable of otherwise, given the complexity of the information. Generically, these methods proceed according to five basic steps:

1. Identify relevant participants in the decision process. This can be a single decisionmaker, multiple decisionmakers, or "stakeholders"-the decisionmakers plus those groups affected by the decision (Edwards and Newman 1982).

2. Identify the dimensions, criteria, or goals that will characterize the alternatives.

3. Generate preference-based weighting schemes.

4. Develop measures by which each of the alternatives is assessed along each of the relevant dimensions.

5. Rank or rate alternatives based on measured outcomes and group preferences and perform analyses. These frequently include marginal analysis of costs and outcomes between alternatives, sensitivity analysis in which changes in the assumptions are tested for their capacity to alter final outcomes, and intergroup differences that compare the utility of different options to different groups and seek satisfying solutions.

Multiattribute studies traditionally have been used in transportation applications to select desired transportation improvements from among a series of proposed projects, or as an approach to predicting individual-level behavior under alternative policy options (Srinivasan et al. 1981; Bunch et al. 1993). Somewhat less common is the use of multiattribute analysis to assess trade-offs between broader goals of a transportation planning process (deNeufville and Keeney 1972). One approach for estimating people's preferences among trade-offs is the Analytic Hierarchy Process (AHP) (Saaty 1980) along with related techniques (Gomes 1989) in which the respondent is presented pairs of attributes and asked to rate the pair in terms of the relative importance of each of its elements.

In the rating scale developed by Saaty (1980), values range from 1/9 (for a case in which a goal is of extremely low importance compared to the other in the pair), 
through 1 (for cases in which the two goals are seen as equally important), to 9 (for cases in which a goal is of extremely high importance relative to the other in the pair). Classical AHP attaches verbal descriptors to the values, such as "moderate importance of one over another" or "demonstrated importance" (Saaty 1980). For the current study, these terms were judged not to be especially meaningful to respondents. Therefore, they were abandoned in favor of a simple row of boxes as shown in Figure 1.

The product of this approach is the estimation of a series of weights summing to unity that gauge the importance an individual places on the various competing goals. These weights may be gauged for consistency under the logic that under perfect consistency:

$$
a_{i k}=a_{i j} x a_{j k} \text { for all elements I, J and } K
$$

For example, if criterion I is seen as twice as important as $\mathrm{J}$ and $\mathrm{J}$ is 4 times as important as $K$, then I should be 8 times as important as $K$. Needless to say, individuals do not demonstrate such perfectly consistent ratios in their responses. AHP methodology thus develops a metric to gauge the distance of an individual's response

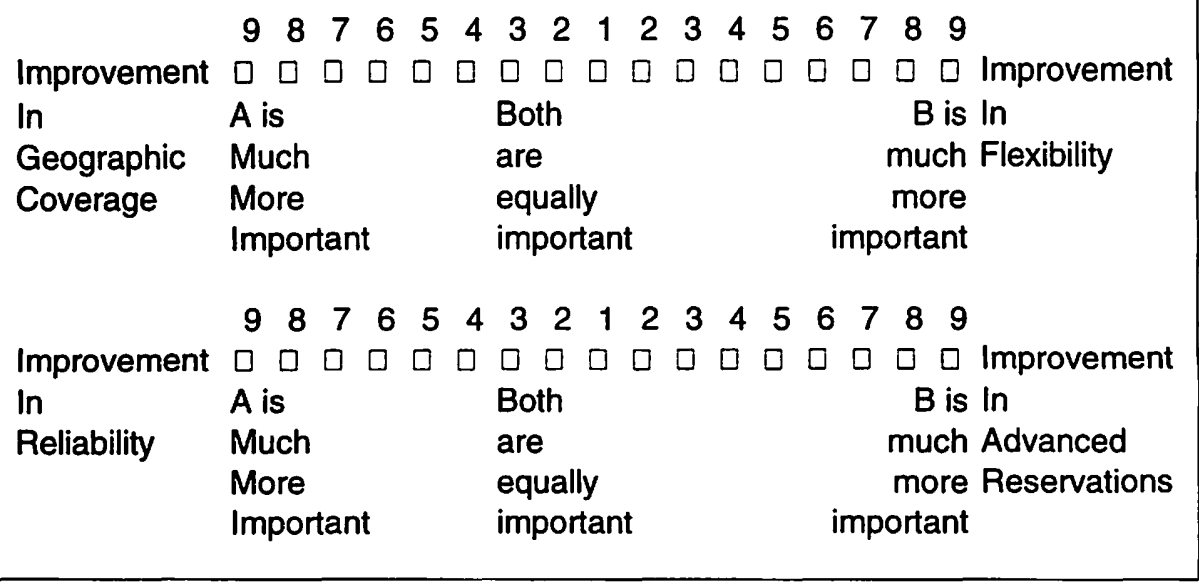

Figure 1. Sample questions from survey. 
set from randomness. A value of 0.1 , or sometimes 0.2 , on this metric (in which 0 indicates "perfectly consistent" and 1 signifies "random") is seen as reflecting adequate consistency to rely on results as reflecting an individual's considered judgment (Saaty and Vargas 1982). When the consistency ratio is higher than 0.2 , the analyst typically offers the respondent the opportunity to clarify some or all of his or her assessments.

\section{Study Methodology}

With the assistance of SMART, a list of groups with a vested interest in public transit in metropolitan Detroit was developed. Representatives of these groups were also involved in this identification process. Group members were contacted for initial phone-based interviews in order to assess (1) the objectives that these groups would define for an APTS implementation such as that planned by SMART, (2) other interest groups that should be represented in the evaluation process, and (3) other individuals associated with those groups that should be represented. Thus, a relatively small initial group expanded to encompass a broad range of individuals and groups with interest in SMART ITS policies and implementation. Through phonebased interviews, eight stakeholder groups were identified for this study, as shown in Table 1. The groups and representatives were selected for their likely interest in SMART policy, rather than for their representation of the population at large. Thus, no attempt is made here to infer to a larger population. The results represent the views of only the identified population of stakeholders in the SMART planning process. In all, 51 individuals were interviewed from groups 1 through 8 listed below.

This study consists of two surveys, each with somewhat different populations. First, subjects were drawn from identified stakeholder groups interested in SMART policy. Individuals were identified and selected within the eight groups listed in Table 1 . The second set of subjects of this study is paratransit passengers. Fifty-one passengers were interviewed on-board from 19 cities within the SMART service area. To select a representative group of passengers, a multi-stage cluster sampling technique was employed (Babbie 1990). Paratransit trips were stratified by service area based on each of four terminals, and by time. For sampled buses, all available passengers were interviewed. Three buses were selected from each terminal (for a 


\section{Table 1 \\ Stakeholder Groups in the SMART Evaluation Process}

Group 1: SMART

Group 2: Customer

Group 3: Local/regional public admin.

Group 4: Federal officials

Group 5: Agencies

Group 6: Business people

Group 7: Citizen groups

Group 8: Non-profit regional organizations
Customer operators, dispatchers, other SMART personnel

Active customers (i.e., board attendees)

City planning, city administration

FHWA, FTA

Agencies interested in using dispatch and related services

People who played key roles in recent millage election

Neighborhood and environmental groups

Urban development foundations, organizations

total of 12 buses) and roughly 4 or 5 passengers were interviewed on each bus (51 in total). Thus, about 13 riders from the service area of each terminal were interviewed.

Initial conversations with members of each of the stakeholder groups were conducted to identify a complete range of goals for SMART's APTS. Group members' stated goals appeared to break down into two dimensions. The first set of goals, identified in Table 2 as "system" goals, pertained to the broadest objectives for SMART system improvements, including ridership expansion, enhancement of interagency cooperation, energy savings, congestion mitigation, and cost reduction. A second set of goals focused more narrowly the dimensions of SMART's paratransit service; these are labeled the "service" goals and are described in Table 3. Two questionnaires were developed for this study; the first addressed five broad policy goals shown in 


\begin{tabular}{|ll|}
\hline \multicolumn{1}{|c|}{$\begin{array}{c}\text { Table } 2 \\
\text { System Goal }\end{array}$} & $\begin{array}{c}\text { Sentified SMART System Goals and Their Definitions, } \\
\text { as Presented to Respondents }\end{array}$ \\
\hline Increase ridership & Increase overall community transit ridership levels \\
Improve coordination & $\begin{array}{l}\text { Improve coordination between SMART and other } \\
\text { transit providers (for example, DOT and other } \\
\text { paratransit) }\end{array}$ \\
Save energy & $\begin{array}{l}\text { Reduce total gasoline and diesel consumption in } \\
\text { motor vehicles in the SMART service area }\end{array}$ \\
Improve cost effectiveness & $\begin{array}{l}\text { Deliver transportation services at a lower cost per } \\
\text { service } \\
\text { Reduce the amount of congestion on the arterials } \\
\text { and expressways in the SMART service area }\end{array}$ \\
\hline
\end{tabular}

Table 2, while the second considered the seven goals directly related to SMART's operations, as shown in Table 3.

The notion of a trade-off between goals is central to the design of this study, as ITS goals and outcomes can have mutually reinforcing or counteracting effects. For example, some strategies that increase ridership may impede cost effectiveness. Similarly, pursuing service goals such as the potential for spontaneous travel may detract from other goals, such as reliability (Levine and Underwood 1996).

To elicit information on stakeholders' valuations of such tradeoffs, a modified AHP approach was employed in this study. Accordingly, the respondent was presented with pairs of goals (Figure 1). To elicit valuation of the service goals, each goal was described by presenting data approximating the current situation and some target for ITS-based improvement in the future (Table 3). This quantitative specification of the goals was a departure from classical AHP, which would typically present two goals - for example, "advance reservations" and "scheduling"-and ask the respondent to compare the goals' relative importance. Faced with this choice, however, 


\begin{tabular}{|c|c|c|}
\hline \multicolumn{3}{|c|}{$\begin{array}{c}\text { Table } 3 \\
\text { Identified SMART Service Goals and Their Definitions, } \\
\text { as Presented to Respondents }\end{array}$} \\
\hline Transit Service & Before Improvement & After Improvement \\
\hline $\begin{array}{l}\text { Advance } \\
\text { reservations }\end{array}$ & $\begin{array}{l}50 \% \text { of advance } \\
\text { reservation requests met }\end{array}$ & $\begin{array}{l}75 \% \text { of advance } \\
\text { reservation requests met }\end{array}$ \\
\hline Scheduling & $\begin{array}{l}\text { Can schedule a ride within } \\
60 \text { min of requested time }\end{array}$ & $\begin{array}{l}\text { Can schedule a ride within } \\
30 \text { min of requested time }\end{array}$ \\
\hline Information & $\begin{array}{l}\text { Takes an avg of } 6 \mathrm{~min} \\
\text { to request a trip }\end{array}$ & $\begin{array}{l}\text { Takes an avg of } 2 \mathrm{~min} \\
\text { to request a trip }\end{array}$ \\
\hline $\begin{array}{l}\text { Weekend \& } \\
\text { evening rides }\end{array}$ & $\begin{array}{l}\text { Cannot get a ride on } \\
\text { evenings \& weekends }\end{array}$ & $\begin{array}{l}30 \% \text { of the time can get a ride } \\
\text { on evenings \& weekends }\end{array}$ \\
\hline $\begin{array}{l}\text { Geographic } \\
\text { coverage }\end{array}$ & $\begin{array}{l}\text { 6-mile limitation to } \\
\text { transfer-free coverage }\end{array}$ & $\begin{array}{l}\text { 10-mile limitation to } \\
\text { transfer-free coverage }\end{array}$ \\
\hline Flexibility & $10 \%$ of ASAP requests met & $30 \%$ of ASAP requests met \\
\hline Reliability & $\begin{array}{l}80 \% \text { of time vehicle } \\
\text { arrives within desig- } \\
\text { nated time window }\end{array}$ & $\begin{array}{l}95 \% \text { of time vehicle } \\
\text { arrives within desig- } \\
\text { nated time window }\end{array}$ \\
\hline
\end{tabular}

the respondent might legitimately wonder: "How much improvement in advance reservations versus how much improvement in scheduling?" Thus, the respondent might have difficulty formulating an appropriate response (Harker and Vargas 1988). The specification of specific, quantified improvements in all goals was an attempt to reduce this ambiguity for the respondent.

Respondents completed the questionnaire on computers in the presence of an interviewer. After all questions were answered, each respondent was shown a figure indicating the initial calculations of his or her weights regarding both the five system goals and the seven service goals described in Tables 2 and 3. All respondents were shown their initial consistency statistics and were given the opportunity to confirm their satisfaction with the initial calculation of weights. At this time, some respon- 
dents revised answers to improve the overall consistency of their responses or to adjust the relative weights of goals to better reflect their preferences.

\section{Preferences of Individuals and Stakeholder Groups}

Depending on one's view of the decisionmaking process, it is possible to view the respondents in this study either as individuals or as members of relevant stakeholder groups. This study adopts both approaches. First, information on the individuals comprising the population as a whole is presented to examine ranges of prevailing opinions on SMART policy among the population studied. Next, individuals are examined for their tendency to represent groups of common interests.

\section{Analysis of Individual Results}

The output of the modified AHP approach described above is an index of the relative importance that each individual implicitly attaches to each goal in the study. The values for an individual sum to unity; i.e., "1" represents the total importance placed on all goals together. Though the primary result of such an analysis is a set of weights for each individual in the study, aggregation of scores is presented as a convenience to avoid presentation of what would otherwise be an indigestibly large amount of data. Means, rather than medians, are generally used to ensure that weighting for groups, like those pertaining to individuals, sum to unity.

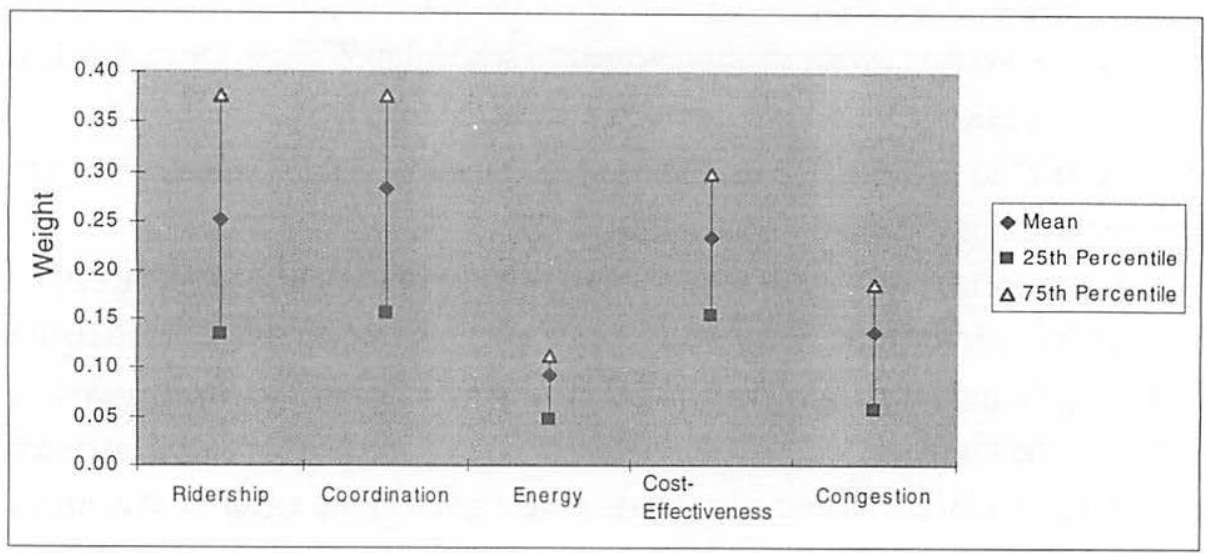

Figure 2. Weight for system goals: means and 25 th and 75 th percentiles. 
Figure 2 presents the means and the 25 th and 75 th percentile weights for each of the five goals across all respondents. For example, the mean weight of the "reduce congestion" goal was 0.14 and the interquartile range was from 0.06 to 0.19 . The greatest weight was placed on improving coordination between SMART and other transportation agencies as the desired system goal, followed by increasing ridership and improving cost effectiveness.

This result agrees well with earlier focus group discussions held with the respondents, as the highest weighted goals tended to dominate the discussions. The goal rankings also seem reasonable when considering the stakeholder groups involved in this survey. Most of the groups and respondents have intimate concerns about transitbased mobility in southeast Michigan. As a result, they are more concerned about immediate system improvements for transit in southeast Michigan than about a range of environmental concerns.

Figure 3 presents parallel findings for the specific service goals. The highest preference was given to reliability, which has a mean value of 0.19 . Interestingly, respondents accorded a relatively high weight to reliability, despite the fact that the base case-i.e., prior to improvement - was quite good ( 80 percent of vehicles arriving within the time window). The lowest rank was placed on information, with a mean value of 0.09 . The respondents appear to be more concerned about time sched-

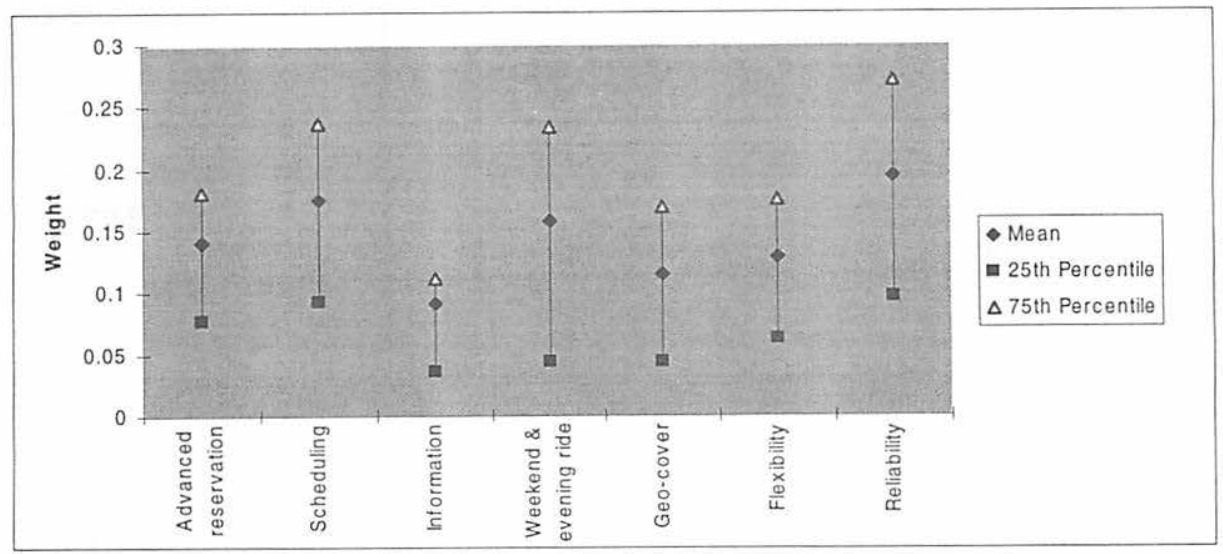

Figure 3 . Weights for service goals: means and 25 th and 75 th percentiles. 
ules and do not want to wait or to be late. Scheduling, weekend and evening rides, and advance reservations show relatively high mean values ( 0.14 to 0.17 )

Flexibility (i.e., immediate service request), expanding the transfer-free distance, and reducing waiting time for trip requests were all somewhat less emphasized, with mean values around 0.10 . In summary, respondents in this study are more concerned about faster and more reliable transportation service, and less concerned about service expansion in terms of geography or time. Of course, potential ridersas opposed to current riders-were not surveyed. Current riders, almost by definition, are having their basic mobility needs met by SMART, at least to some extent. People who have regular needs for travel outside of the constraints of the current SMART system, however, may weight goals differently.

\section{Analysis of Identified Stakeholder Groups}

An implicit assumption of a planning process that explicitly involves stakeholder groups is one of similarity of interests within identifiable groups. Under this framework, these groups - as groups, not as aggregations of individuals - are presumed to be major players in the process of policymaking. This section analyzes the extent to which the representatives form groups and the extent to which these groups match their identified affiliations. Figure 4 presents mean weightings for SMART

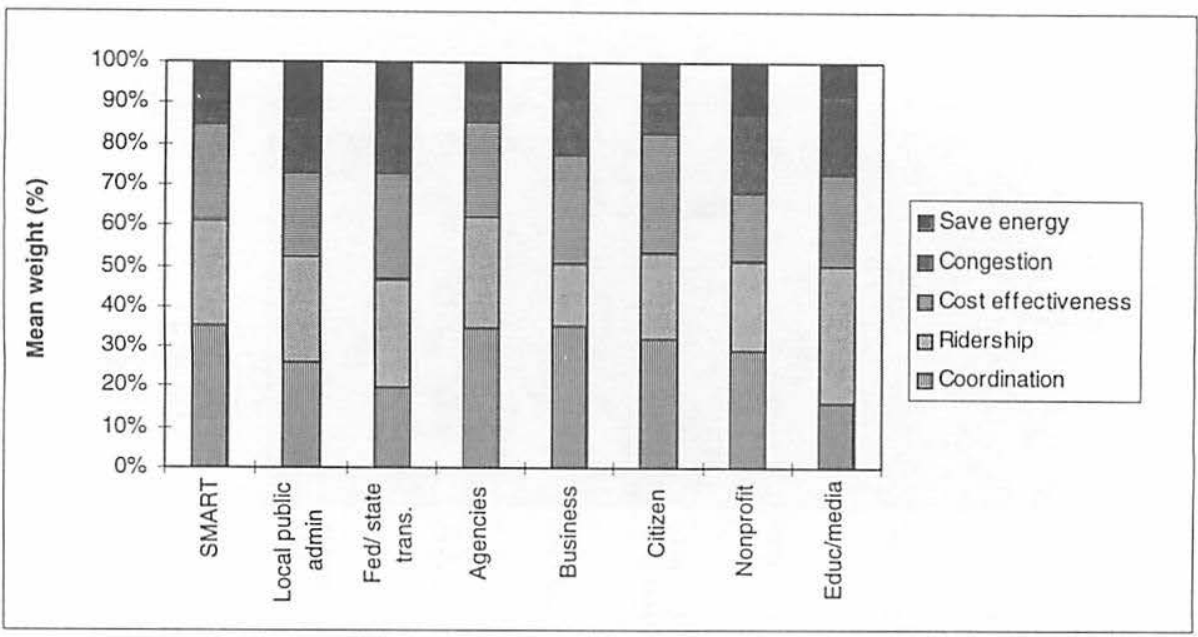

Figure 4. Valuation of system goals by stakeholder groups. 
system goals by the nine stakeholder groups. Each group's valuation of all goals combined is set to 100 percent. How each group divides up this total valuation among the various goals is represented by the heights of the bar segments.

Overall, there appears to be greater similarity than difference between the groups. Most of the groups rate improving coordination highly, though SMART, agencies, and business groups tend to give it a higher rating than others. The federal/ state transportation and media/education groups rate increasing ridership and cost effectiveness highly compared to others. Improving cost effectiveness and increasing ridership were rated similarly among various groups. Most groups give energy savings the lowest value, but non-profit organizations and local public administrators give higher ranks than other groups for both goals. Regarding congestion, the media/education, non-profit, and federal/state transportation groups indicate higher values compared to other groups.

The valuation of quality of service goals appears to have more differences among groups compared to system goals. Most groups rate improving reliability highly-around a mean value of 0.20 -while top ranking by passengers was given to scheduling ( 0.20$)$, by businesses to weekend and evening rides $(0.31)$, and by citizen groups to geographic coverage (0.25). Compared to other groups, passengers gave the lowest value to reliability. Given that most passengers on paratransit buses are seniors and persons with disabilities, many of whom are not currently employed, this outcome may be due to a fair amount of flexibility in their schedules. Perhaps the most notable result of this analysis is that business groups place a high value on weekend and evening rides, with a group mean of 0.31 . Other groups (e.g., SMART officials and the public sector) show less interest in this goal. Business groups may prefer extending service hours for their employees, as well as their customers.

Geographic coverage receives a high valuation from citizen groups but other groups appear somewhat less interested in this goal. Most groups rate information as their lowest value but the federal/state transportation group gives it a relatively higher value (0.13) compared to other groups. SMART employees tend to give lower values to both weekend and evening rides and geographic coverage while giving higher ranks to reliability, advance reservations, and scheduling. Passengers give 
higher ranks to scheduling, weekend and evening rides, and advance reservation factors related to ridership. The federal/state transportation groups indicate higher values for scheduling and flexibility, similar to the valuation given by the local and regional public administration group. Valuation of geographic coverage and improving scheduling varied widely among groups, while reliability and information showed similar values among groups.

Emerging from this breakdown of preference is a distinction between desired improvements on the basis of the respondent's affiliation. Families of improvements may be categorized as expansive (i.e., expanding service in the dimensions of time, geographic coverage, or flexibility) or incremental (i.e., improving service that is already provided, in terms of scheduling or reliability). Citizens' groups, businesses, and agencies appear to be more expansive in their vision, while SMART personnel appear to prefer a more incremental approach. Current passengers' valuations also appear more incremental in tone. This outcome probably is attributable to the self-

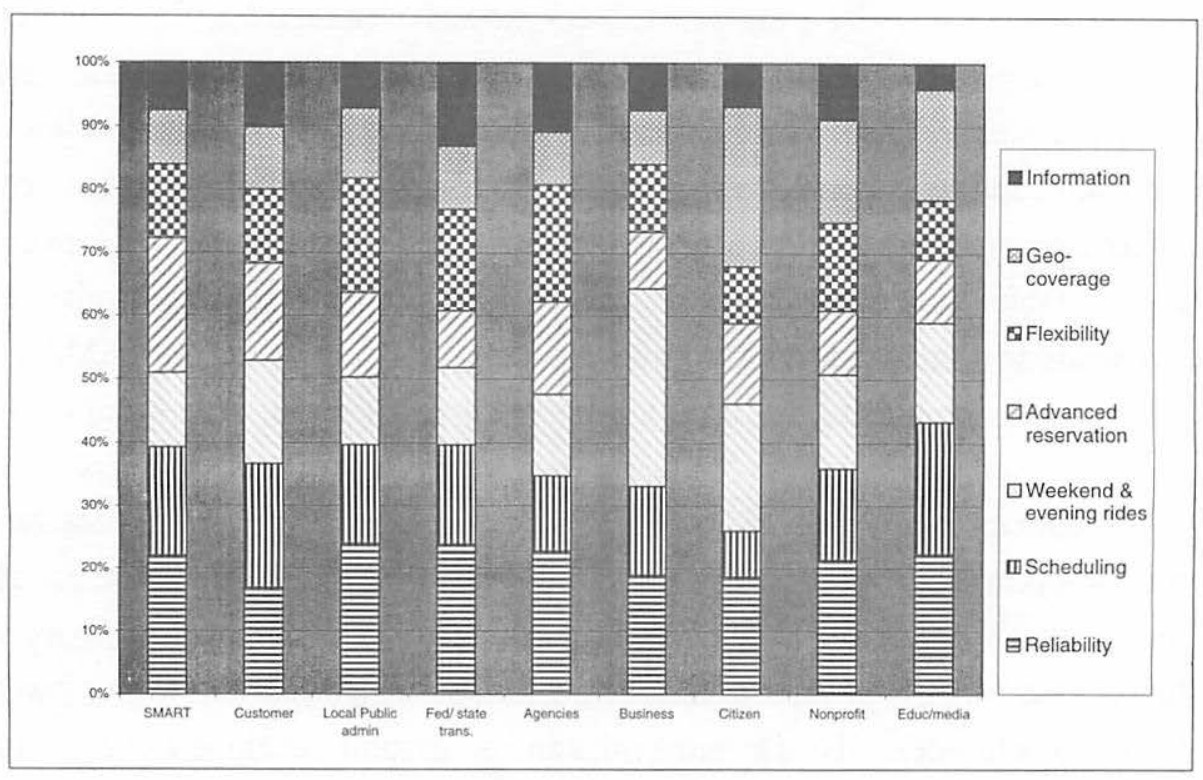

Figure 5 . Valuation of service goals by stakeholder groups. 
selection that occurs among riders - those who are current customers are those whose basic destination and travel times are being served through current service.

\section{Impact of Group Affiliation on Transit Preferences}

To further explore the significance of group membership on policy valuation, stepwise multiple regression was performed in an attempt to predict valuation of service improvement goals on the basis of individuals' characteristics, as well as stakeholder group affiliation. Table 4 presents the regression result for the four (out of seven) service goals for which at least 10 percent of the variance could be explained by group membership and demographic characteristics. The results tend to support the findings reported above: for only four goals was stakeholder group affiliation a statistically significant predictor of valuation of SMART service goals $(\mathrm{p}<0.05)$.

First, SMART affiliation and age are positively associated with improving advance reservations. Thus, SMART staff and older people appear to be more interested in improving than in expanding current service. Second, views on scheduling seem to be positively associated with membership in the customer group; this finding may have a similar interpretation to that associated with advance reservations. Third, the business group shows an interest in improving weekend and evening rides relative to other groups. Conversely, transportation groups as a whole (including SMART, lo$\mathrm{cal} /$ regional public administration, and federal/state transportation officials) show a negative association with weekend and evening rides. The focus group discussions help explain this result: these groups are concerned about spreading resources too thinly over expanded service. Finally, the citizens' groups and nonprofit organizations show an interest in improving the geographic coverage of transfer-free travel. In other words, they appear interested in allowing their clients to travel greater distances with less hassle. Quite possibly, such an improvement would allow these organizations to extend the geographic extent of their service provision.

Among demographic variables, only age was included as a statistically significant predictor variable. Age is positively associated with valuation of advance reservations, while showing a negative relationship with valuation of weekend and evening rides. It may be that older people are more concerned about improving paratransit 


\section{Table 4}

Stepwise Regressions Predicting Valuation of Service Improvement Goals (t-statistics in parenthesis)

\begin{tabular}{|c|c|c|c|c|}
\hline & & Dependent & Variables & \\
\hline $\begin{array}{l}\text { Independent } \\
\text { Variables }\end{array}$ & $\begin{array}{c}\text { Ln Improving } \\
\text { Advance } \\
\text { Reservation }\end{array}$ & $\begin{array}{l}\text { Improving } \\
\text { Scheduling }\end{array}$ & $\begin{array}{c}\text { Ln Improving } \\
\text { Weekend \& } \\
\text { Evening Rides }\end{array}$ & $\begin{array}{c}\text { Ln Improving } \\
\text { Geographic } \\
\text { Coverage }\end{array}$ \\
\hline Constant & $-2.92(-14.09)$ & $0.16(11.38)$ & $-1.31(-3.7)$ & $-2.60(-33.19)$ \\
\hline Age & $0.14(3.67)$ & & & $-0.18(-3.03)$ \\
\hline \multicolumn{4}{|l|}{ Dummies: } & \\
\hline Customer & & $0.04(2.09)$ & & \\
\hline \multicolumn{5}{|l|}{ Major agencies } \\
\hline Business group & & $\underline{0.66(1.48)}$ & & \\
\hline Citizen group & $-0.09(-2.09)$ & & $1.20(3.84)$ & \\
\hline Non-profit org. & & & $0.66(2.10)$ & \\
\hline Transportation & & $-0.32(-1.30)$ & & \\
\hline $\mathbf{R} 2$ & 0.16 & 0.11 & 0.12 & 0.16 \\
\hline Adjusted R2 & 0.14 & 0.09 & 0.09 & 0.14 \\
\hline
\end{tabular}

* When the skewness of dependent variable is greater than 1 , natural log transformation was performed. Based on the natural log estimations described in above Table 8 , the models may be presented in the following fashion:

Estimated Improving Advance Reservation: $0.05 * \mathrm{e}^{0.14 A_{z e} *} \mathrm{e}^{0.67 \text { SMART }}$

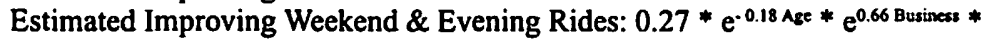
$\mathrm{e}^{-0.32 \text { Trans. }}$

Estimated Improving Geographic Coverage: $0.07 * \mathrm{e}^{1.20 \text { Citizen }} * \mathrm{e}^{0.66 \text { Non-Profin }}$

* Underlined dummy variable in Weekend \& Evening Rides are statistically significant only when $\mathrm{P}<0.2$.

* Media/education is the omitted stakeholder group dummy variables. 
within its current time limitations, while younger people prefer extending temporal coverage. In general, the results of stepwise regression are consistent with the results of means comparisons.

\section{Conclusion}

This study aims to understand how SMART and similar transit organizations may improve services for their customers and communities by using APTS. Several major themes emerge from the analyses above.

\section{Use of Stakeholder Preference Data in the APTS Planning Process}

This evaluation does not presume that there exists a single set of values upon which a judgment of efficacy of a transit organization can rest. Rather, the evaluation acknowledges the heterogeneity of interests in the planning efforts of a transit organization, the constituencies that influence it or may be impacted by its decisions, and the more general audience for which the evaluation will have some appeal. Transit officials are interested in tracking the political environment, including the viewpoints of riders, the U.S. DOT, and national transportation policy leaders. The evaluation was designed to capture these multiple interests through the application of multiattribute value and integrative analysis techniques. These techniques are designed to clarify similarities and differences in values between individuals and groups, to explore the potential for creating new implementation options, and to evaluate new and baseline options in terms of the stakeholders' values.

\section{Relative Consensus Among Groups}

Although stakeholders were drawn from a broad range of interest groups, including riders, SMART employees, the business community, agency representatives and more, there was less variation among groups in preferences than might be expected. Statistically significant differences among groups were rare, indicating a fair degree of common ground in desired outcomes of transit planning. This may be good news for decisionmakers trying to forge system goals meeting the needs of a broad array of groups. 


\section{Importance of Scheduling and Advance Reservations}

The ability to provide for the trips that people request, referring both to the accommodation of trips and the match between the requested and the scheduled times, were important goals across various stakeholder groups. Similarly, provision of reliable service was generally valued highly. Information provision, a focus of much of SMART's efforts in the early phase of the project, appears to be a lower priority. Thus, to the extent that automatic scheduling and dispatch assist improved scheduling, trip reservation, and routing, it is likely to meet stakeholders' preferences. If systems focus largely on information provision, then stakeholders' goals will not be met as well.

\section{Focus on Mobility-Related Goals}

Two levels of goals were considered here: broad system-wide goals (e.g., energy savings, interagency coordination, congestion reduction) and specific service characteristics such as advance reservations, scheduling, and reliability. Emerging from the broader perspective is a view that SMART's planning activities need to be oriented to effective mobility provision, per se, rather than related goals of energy savings or congestion reduction. Large numbers of people in the SMART service area are dependent on SMART and other providers for their mobility needs, and intelligent transportation systems are seen as potential elements of meeting those needs. Furthermore, given transit's low mode share in the region, in the near term, incremental changes in transit policy can have little effect on energy use or congestion.

\section{Expansiveness versus Incrementalism}

The goals discussed in both the quantitative and qualitative analyses can be divided into two principal families:

1) those goals that pertain to operating current service more effectively, and

2) those goals that pertain to expanding the types of service that SMART is able to offer.

The former view can be referred to as the incremental view, while the latter may be seen as the expansive position. The expansive position appears most clearly among citizens' groups, social service agencies, and business people. These groups are keenly 
interested in expansion of the geographic range that is accessible by SMART paratransit and expansion of the flexibility with which trips can be requested. Notably, the business community is particularly interested in expansion of the hours of service, presumably to facilitate travel by customers or employees during evenings and weekends.

The more incremental view is held by transportation professionals and SMART employees who are aware of the constraints under which they work. Current passengers also appear to be more incremental than expansive. At first glance this may be surprising, given that passengers are largely dependent on transit for their mobility needs. It seems that a process of selection has already occurred; current passengers are those for whom SMART more or less serves needed destinations and travel times. Furthermore, as current customers, passengers may also share an understanding of system tradeoffs and constraints.

Assessment of the appropriate balance between the expansive and the incremental views will be a continuing process that will undoubtedly occupy transit organizations for years to come. Methodologies established in the current study can assist in this process by identifying relevant views and perceptions of groups and individuals who are intimately involved in and concerned with the provision of transit and paratransit-based mobility.

\section{References}

Aldenderfer, M. S., and R. K. Blashfield. 1984. Cluster analysis. Beverly Hills, CA: Sage Publications, Inc.

Babbie, E.A. 1990. Survey research methods, 2nd edition. Belmont, CA: Wadsworth Publishing Co.

Bunch, D. S., M. Bradley, T. F. Golob, and R. Kitamura. 1993. Demand for clean-fuel vehicles in California:A discrete-choice stated preference pilot project. Transportation Research 27A: 237-253.

Chen, K., and S. E. Underwood. 1988. Integrative analytical assessment: A hybrid method for facilitating negotiations. Negotiation Journal, April 1988: 183-197. 
de Neufville, R., and R. L. Keeney. 1972. Use of decision analysis in airportdevelopment in Mexico City. In A. W. Drake, R. L. Keeney, and M. P. Morst (eds.), Analysis of public systems. Cambridge, MA:MIT Press.

Downs, A. 1992. Stuck in traffic: Coping with peak-hour congestion. Washington, D.C.: Brookings Institute; Cambridge, MA: Lincoln Institute of Land Policy.

Edwards, W., and J. R. Newman. 1982. Multiattribute evaluation. Newbury Park, CA: Sage Publications.

Giuliano, G. 1985. A multicriteria method for transportation investment planning. Transportation Research 19A:29-41.

Gomes, L. F.A. M. 1989. Multicriteria ranking of urban transportation system alternatives. Journal of Advanced Transportation 23: 43-52.

Gordon, D. 1992. Intelligent vehicle/highway systems: An environmental perspective. In J. L. Gifford, T.A. Horan, and D. Sperling, eds. Transportation, information technology and public policy: Institutional and environmental issues in IVHS. Proceedings of TVHS Policy:A Workshop on Institutional and Environmental Issues. Fairfax, VA: The Institute of Public Policy, George Mason University.

Harker, P. T., and L. G. Vargas. 1988. The theory of ratio = scale estimation: Saaty's analysis hierarchy process. Management Science 33: 1383-1403.

IVHS America. 1992. Strategic plan for Intelligent Vehicle-Highway Systems in the United States. Report NumberIVHS-AMER-92-3.

Keeney, R. L., and H. Raiffa. 1976. Decisions with multiple objectives: Preferences and value tradeoffs. New York: Wiley Publishing Company.

Khattak, Asad J., H. Noeimi, and H.Al-Deek. 1996. A taxonomy for advanced public transportation systems. Journal of Public Transportation 1(1):39-102.

Lister, M., C. L. Schweiger, and I. Keaveny. 1995. Getting smarter with ITS: Improved paratransit operations using integrated scheduling and dispatch and automatic vehicle location at SMART. Prepared for ITS America Fifth Annual Meeting, Washington, D.C.

MITRE. 1995. Assessment of ITS benefits: Early results. Report No.: FHWA/JPO-96/00, Federal Highway Administration, U.S. Department of Transportation, Washington, D.C.

Roy, B., and J.C. Hugonnard. 1982. Ranking of suburban line extension projects on the Paris Metro System by a multicriteria method. Transportation Research 16A:301-312.

Saaty, T. L., and L. G. Vargas. 1982. The logic of priorities: Applications in business, energy, health and transportation. Boston: Kluwer-Nijhoff Publishing. 
Saaty, T.L. 1980. The analytic hierarchy process: Planning, priority setting, resource allocation. NewYork:MoGraw-Hill.

Saaty, T. L. 1976.Axiomatic foundation of the analytic hierarchy process. Management Science 32: 841-855.

Saaty, T. L., and K. P. Kearns. 1985. Analytical planning: The organization of systems. NewYork: Pergamon Press.

Sebenius, J.K. 1984. Negotiating the law of the sea. Cambridge, MA: Harvard University Press.

Shladover, S. 1993. Potential contributions of Intelligent Vehicle/Highway Systems (IVHS) to reducing transportation's greenhouse gas production. Transportation Research 27A: 207216.

Srinivasan, V., P. G. Flachsbart, J. S. Dajani, and R. G. Hartley. 1981. Forecasting the effectiveness of work-trip gasoline conservation policies through conjoint analysis. Journal of Marketing 45: 157-172.

Underwood, S. 1994. FAST-TRAC: Evaluating an integrated Intelligent Vehicle-Highway System. In Proceedings for Fourth Annual Meeting of IVHSAmerica, April 17-20 1994,Atlanta, GA.

\section{About the Authors}

Jonathan LeVINE is an Associate Professor in the Urban and Regional Planning Program at the University of Michigan

SOONAE PARK is an Instructor in the Public Administration Department, Sang-Myoung University, Korea.

STEVEN E. UnderwOOd is an Assistant Research Scientist in the Department of Electrical Engineering and Computer Science at the University of Michigan.

RICHARD R.WALLACE is a doctoral candidate in Urban, Technological, and Environmental Planning and a researcher with the Intelligent Transportation Systems Laboratory, both at the University of Michigan. 